\title{
Efficacy and Safety of Ephedra and Ephedrine for Weight Loss and Athletic Performance A Meta-analysis
}

\begin{tabular}{l}
\hline Paul G. Shekelle, MD, PhD \\
\hline Mary L. Hardy, MD \\
\hline Sally C. Morton, PhD \\
\hline Margaret Maglione, MPP \\
\hline Walter A. Mojica, MD, MPH \\
\hline Marika J. Suttorp, MS \\
\hline Shannon L. Rhodes, MFA \\
\hline Lara Jungvig, BA \\
\hline James Gagné, MD
\end{tabular}

U SE OF EPHEDRINE ALKALOIDcontaining products to promote weight loss or to enhance athletic performance has garnered a great deal of recent attention, due in part to a number of wellpublicized adverse events reportedly associated with the use of ephedra- or ephedrine alkaloid-containing products. ${ }^{1-3}$ These reports have led several groups to ask the US Food and Drug Administration (FDA) to ban the production and sale of ephedra products. ${ }^{4} \mathrm{Ad}-$ vocates counter that ephedra is safe and effective. ${ }^{5}$ The US Department of Health and Human Services requested this synthesis of available evidence regarding efficacy and safety of ephedra use to clarify the existing state of the science on ephedrine alkaloids. The National Institutes of Health will use this information to guide an expanded research effort to better understand the safety of ephedrine alkaloids. ${ }^{6}$

See also p 1568 and Patient Page.

Context Ephedra and ephedrine sometimes are used for weight loss or enhanced athletic performance, but the efficacy and safety of these compounds are uncertain.

Objective To assess the efficacy and safety of ephedra and ephedrine used for weight loss and enhanced athletic performance.

Data Sources We searched 9 databases using the terms ephedra, ephedrine, adverse effect, side effect, efficacy, effective, and toxic. We included unpublished trials and non-English-language documents. Adverse events reported to the US Food and Drug Administration MedWatch program were assessed.

Study Selection Eligible studies were controlled trials of ephedra or ephedrine used for weight loss or athletic performance and case reports of adverse events associated with such use. Eligible studies for weight loss were human studies with at least 8 weeks of follow-up; and for athletic performance, those having no minimum follow-up. Eligible case reports documented that ephedra or ephedrine was consumed within 24 hours prior to an adverse event or that ephedrine or an associated product was found in blood or urine, and that other potential causes had been excluded. Of the 530 articles screened, 52 controlled trials and 65 case reports were included in the adverse events analysis. Of more than 18000 other case reports screened, 284 underwent detailed review.

Data Extraction Two reviewers independently identified trials of efficacy and safety of ephedra and ephedrine on weight loss or athletic performance; disagreements were resolved by consensus. Case reports were reviewed with explicit and implicit methods.

Data Synthesis No weight loss trials assessed duration of treatment greater than 6 months. Pooled results for trials comparing placebo with ephedrine $(n=5)$, ephedrine and caffeine $(n=12)$, ephedra $(n=1)$, and ephedra and herbs containing caffeine $(n=4)$ yielded estimates of weight loss (more than placebo) of $0.6(95 \%$ confidence interval, $0.2-1.0), 1.0(0.7-1.3), 0.8(0.4-1.2)$, and $1.0(0.6-1.3) \mathrm{kg} / \mathrm{mo}$, respectively. Sensitivity analyses did not substantially alter the latter 3 results. No trials of ephedra and athletic performance were found; 7 trials of ephedrine were too heterogeneous to synthesize. Safety data from 50 trials yielded estimates of 2.2- to 3.6-fold increases in odds of psychiatric, autonomic, or gastrointestinal symptoms, and heart palpitations. Data are insufficient to draw conclusions about adverse events occurring at a rate less than 1.0 per thousand. The majority of case reports are insufficiently documented to allow meaningful assessment.

Conclusions Ephedrine and ephedra promote modest short-term weight loss $(\approx 0.9$ $\mathrm{kg} / \mathrm{mo}$ more than placebo) in clinical trials. There are no data regarding long-term weight loss, and evidence to support use of ephedra for athletic performance is insufficient. Use of ephedra or ephedrine and caffeine is associated with increased risk of psychiatric, autonomic, or gastrointestinal symptoms, and heart palpitations.

JAMA. 2003;289:1537-1545

www.jama.com

Author Affiliations are listed at the end of this article. Corresponding Author and Reprints: Paul G. Shekelle, MD, PhD, Southern California Evidence-based
Practice Center-RAND, 1700 Main St, PO Box 2138, Santa Monica, CA 90407-2138 (e-mail: shekelle @rand.org). 


\section{METHODS \\ Identification and Synthesis of Controlled Trials}

Since ephedrine is believed to be the alkaloid most responsible for the effects of herbal ephedra, we searched for controlled trials of ephedrine or ephedra that assessed either weight loss or athletic performance in humans.

We searched the following electronic databases in March and April 2001: MEDLINE (1965-2001), EMBASE (1974-2001), BIOSIS (1969-2001), Allied and Complementary Medicine Database (AMED) (1984-2001), MANTIS (1880-2000), the Cochrane Controlled Clinical Trials Register Database, and International Pharmaceutical Abstracts (1970-2001), PASCAL (1973-2001), and SCISEARCH (19741989, 1990-2001). Search terms included ephedra, ephedrine, adverse effect, side effect, efficacy, effective, and toxic. The specific search strategies are displayed in an Appendix of detailed methods available at http://www.rand.org/health /epc. We then searched the reference lists of each retrieved article. There was no language restriction. We also searched for unpublished or "gray" literature by posting announcements in the journals Phytomedicine and Herbalgram and by writing to numerous regulatory officials and herbal experts in other countries seeking unpublished evidence.

Two trained reviewers independently reviewed titles, abstracts, and articles to identify controlled trials in humans assessing weight loss or athletic performance. Disagreements were resolved by consensus. Articles meeting these inclusion criteria were then reviewed in duplicate to abstract data regarding study design and execution, participants, therapies, and outcomes (abstracted variables are available at http://www.rand.org/health/epc). To assess efficacy in weight loss, we included only trials with at least 8 weeks' duration of treatment, because shorter durations of treatment are thought to be less informative. To assess adverse events, we included all identified controlled trials for either indication. Articles were not masked for author or journal.
Trials assessing athletic performance were too heterogeneous to support statistical pooling. For the weight loss and adverse events analyses, we abstracted the relevant outcome data (weight loss, occurrence of an adverse event). Weight loss outcomes were pooled in clinically similar groups of trials. We first verified that weight loss was linear over the range of time for which data were available by comparing pooled monthly rates of weight loss based on 2- month, 3- month, and 4-month data separately. We then pooled monthly weight loss effect sizes using a random-effects model. ${ }^{7}$ We also pooled percentage weight loss from baseline in the treatment groups for comparison with other weight loss products.

We tested for a dose effect using a meta-regression model, ${ }^{8}$ defining an ephedrine low dose as 10 to $20 \mathrm{mg} / \mathrm{d}$; medium dose as 40 to $90 \mathrm{mg} / \mathrm{d}$; and high dose as 100 to $150 \mathrm{mg} / \mathrm{d}$.

We conducted sensitivity analyses to determine the robustness of our conclusions. One sensitivity analysis divided the trials into those with less than $20 \%$ attrition compared with all others. A second analysis dropped an included trial by Moheb et $\mathrm{al}^{9}$ that presented data in abstract form and required sample-size assumptions. A third analysis assessed only those trials scoring 3 or greater on the Jadad scale of quality, ${ }^{10,11}$ which gives points based on randomization, blinding, and description of withdrawals, and ranges from 0 (poor) to 5 (good). In other settings a threshold of 3 has been shown to be related to bias. ${ }^{11}$ We also performed sensitivity analyses where relevant by dropping trials that included other medications (aspirin, synephrine) with ephedrine. The sensitivity analysis based on study quality was specified a priori; all others were post hoc after examining the relevant studies.

For the safety analysis, we estimated the pooled odds ratio (OR) for clinically related groups of symptoms using exact conditional inference methods because of the rarity of events. To assess dose response, we conducted a stratified analysis with the dose strata defined as for the efficacy analysis.
We assessed the possibility of publication bias by evaluating a funnel plot of effect sizes for asymmetry, which results from the nonpublication of small, negative trials. Because graphical evaluation can be subjective, we also conducted an adjusted rank correlation test $^{12}$ and a regression asymmetry test. ${ }^{13}$

We conducted all analyses using Stata $^{14}$ except for the exact analyses, which were conducted using StatXact, ${ }^{15}$ with $P<.05$ considered significant. A more detailed explanation of these methods is available at http://www.rand.org /health/epc.

Because the randomized trials had, even in aggregate, low statistical power to assess the possibility of rare adverse events, we searched for and reviewed case reports of adverse events associated with use of ephedrine or ephedra. Case reports cannot be considered, except in extraordinary circumstances, to be conclusive evidence of a cause-andeffect relationship. Case reports can, however, be useful to establish the potential for a causal relationship. We assessed all reports for ephedrine and ephedra in the FDA MedWatch files as of September 30, 2001, all case reports we identified in published literature, and a very large file of symptoms reported to a manufacturer of ephedra-containing dietary supplements. All case reports were screened and we reviewed in detail all reports of death, myocardial infarction/acute coronary syndromes/ other cardiac symptoms, cerebrovascular accident/transient ischemic attack/ other neurologic symptoms, seizure, and serious psychiatric symptoms.

We searched for documentation that (1) an adverse event had occurred; (2) the subject had consumed ephedra or ephedrine within 24 hours prior to the adverse event or that a toxicological examination had revealed ephedrine or one of its associated products in the blood or urine; and (3) an adequate investigation had evaluated for and excluded other potential causes. Cases meeting all these criteria were labeled "sentinel events." Cases meeting the first 2 criteria that had other possible causes of the event were labeled "pos- 
sible sentinel events." We used the clinical judgment of expert clinicians to assess whether other causes had been adequately evaluated and excluded.

\section{RESULTS}

FIGURE 1 illustrates the flow of literature reviewed. We identified 550 articles. These included 3 clinical trials that were unpublished at the time our review was undertaken; one has since been published. We were unable to obtain 20 articles; from their titles and keywords none appeared to be clinical trials of ephedrine or ephedra.

\section{Efficacy: Weight Loss}

We identified 44 controlled trials (51 articles) that assessed ephedra, ephedrine, or ephedrine and other compounds used for weight loss. Of these, 18 trials were excluded from pooled analysis because they had a duration of treatment shorter than 8 weeks; another 6 trials were excluded for other reasons (eg, insufficient data for metaanalysis; crossover design without provider outcomes at the crossover point).

For the remaining 20 trials, we classified the comparisons made into 6 categories: ephedrine vs placebo, ephedrine and caffeine vs placebo, ephedrine and caffeine vs ephedrine alone, ephedrine vs another active weight loss pharmaceutical, ephedra vs placebo, ephedra with herbs containing caffeine vs placebo. We found no trials of ephedra vs another active weight loss therapy. Details of the 19 placebocontrolled studies are presented in TABLE 1.

Ephedrine vs Placebo. We identified 5 trials containing 6 comparisons that assessed the effect of ephedrine vs placebo. ${ }^{9,22,25,28,29}$ All 5 were described as randomized, placebo-controlled trials with results reported at 3 or 4 months' duration of treatment. The randomeffects pooled estimate of the rate of weight loss was $0.6 \mathrm{~kg}$ per month above weight lost with placebo (95\% confidence interval [CI], 0.2-1.0) (FIGURE 2). The pooled average percentage weight loss in the ephedrine-treated patients, compared with pretreatment weight, was $11 \%$ at 4 months. A sensitivity analysis of only those trials scoring 3 or greater on the Jadad scale yielded a pooled estimate of effect substantially lower than that yielded by the main analysis (weight loss rate, $0.2 \mathrm{~kg}$ per month); this difference (compared with the main analysis) was statistically significant $(P=.049)$. All of these trials had an attrition rate of greater than $20 \%$ and therefore no sensitivity analysis on attrition could be performed. A final sensitivity analysis dropping the trial by Moheb et $\mathrm{al}^{9}$ did not materially change these results. In our dose analysis, only high doses of ephedrine produced a weight loss that was statistically significantly greater than zero, and the difference in weight loss between medium-dose trials and high-dose trials ap-

Figure 1. Flow of Reviewed Literature

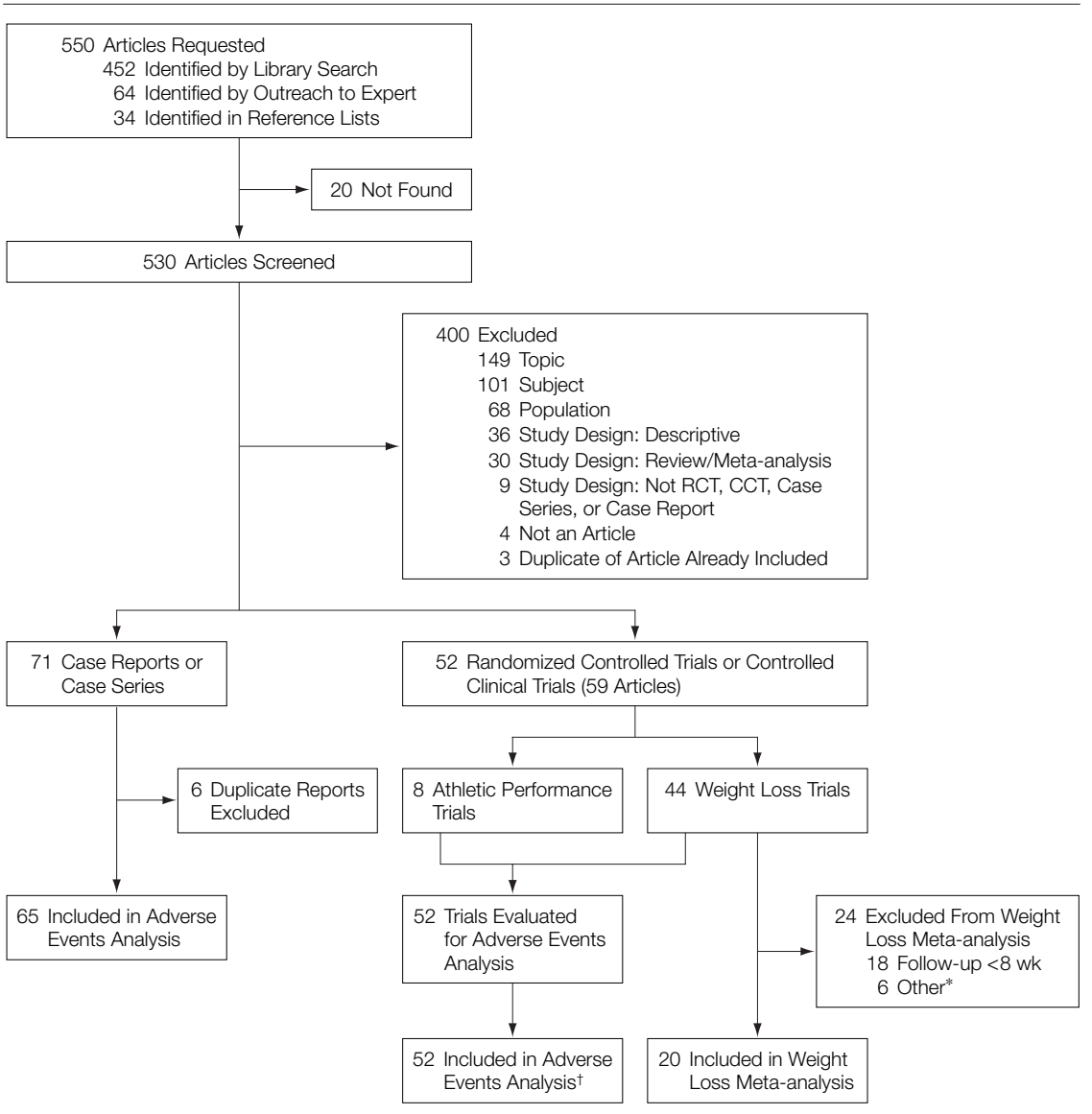

RCT indicates randomized cointrolled trial; CCT, controlled clinical trial.

*Various reasons (see "Methods" section).

t2 studies had no placebo group and therefore did not contribute to the odds ratio meta-analysis. proached statistical significance $(P=.05)$. Neither graphical assessment nor statistical tests yielded evidence of publication bias $(P=.45$ for rank test; $P=.82$ for regression test).

Ephedrine and Caffeine vs Placebo. We identified 12 trials that assessed the effect of ephedrine and caffeine vs placebo for weight loss, ${ }^{*}$ with results reported at between 2 and 4 months' duration of treatment. Seven were described as randomized, doubleblind, placebo-controlled trials. The random-effects pooled estimate of the rate of weight loss was $1.0 \mathrm{~kg}$ per month above weight lost with placebo (95\% CI, 0.7-1.3) (Figure 2). The pooled average percentage weight loss in the ephed-

*References 16, 19, 21-24, 26, 27, 29-31. 
rine- and caffeine-treated patients, compared with pretreatment weight, was $11 \%$ at 4 months. A sensitivity analysis of only those trials that scored 3 or greater on the Jadad scale yielded a result similar to that yielded by the main analysis. Another sensitivity analysis of only those trials that had less than $20 \%$ attrition also yielded a similar result. A third sensitivity analysis dropping the trial by Moheb et $\mathrm{al}^{9}$ did not change the primary analysis. Neither did sensitivity analyses that dropped trials that included synephrine or aspirin. In our dose analysis, there was a trend toward increased weight loss with higher doses (weight loss greater than that lost with placebo of $0.9,0.9$, and $1.4 \mathrm{~kg} / \mathrm{mo}$ for low, medium, and high doses, respectively) but these differences were not statistically significant. Neither graphical assessment nor statistical tests revealed publication bias $(P=.30$ for rank test; $P=.12$ for regression test).

Ephedrine and Caffeine vs Ephedrine. We identified 3 trials that included comparisons that assessed a combination of ephedrine and caffeine vs ephedrine alone. ${ }^{9,22,29}$ All 3 had attrition rates of greater than $20 \%$. The random-effects pooled estimate of weight loss was $0.4 \mathrm{~kg}$ per month above weight lost with ephedrine alone (95\% CI, 0.02-0.7) (data not shown). There were too few trials to perform any sensitivity analysis.

Ephedrine vs Another Active Weight Loss Pharmaceutical. We identified 2 trials that compared ephedrine vs another active weight loss therapy. ${ }^{26,32}$ Both took place in Denmark and did not have sufficient statistical power to detect even a 30\% difference between groups. One trial compared dexfenfluramine with a combination of ephedrine and caffeine. ${ }^{32}$ At 15 weeks of treatment there was no statistically significant difference in weight loss between groups. The second trial compared the Elsinore pill (a prescription containing ephedrine and caffeine) with diethylpropion

Table 1. Placebo-Controlled Trials Used in Meta-analysis

\begin{tabular}{|c|c|c|c|c|c|c|c|}
\hline \multirow[b]{2}{*}{ Source } & \multirow[b]{2}{*}{$\begin{array}{l}\text { Jadad } \\
\text { Scale Score }\end{array}$} & \multirow[b]{2}{*}{ Intervention (Dose, mg) } & \multirow[b]{2}{*}{$\begin{array}{c}\text { Trial } \\
\text { Duration }\end{array}$} & \multicolumn{2}{|c|}{ Sample Size, No. } & \multicolumn{2}{|c|}{$\begin{array}{l}\text { Average Weight Loss, } \\
\text { (SD), kg }\end{array}$} \\
\hline & & & & Placebo & Intervention & Placebo & Intervention \\
\hline Astrup et al, ${ }^{16} 1992$ & 2 & Ephedrine (60) and caffeine (600) & $8 w k$ & 8 & 8 & $8.4(2.9)$ & $10.1(1.0)$ \\
\hline Boozer et al, ${ }^{17} 2002$ & 5 & $\begin{array}{l}\text { Ephedrine from ma huang (86.4) } \\
\text { and caffeine from kola nut (196) }\end{array}$ & $24 w k$ & 84 & 83 & $2.6(3.2)$ & $5.3(5.0)$ \\
\hline Boozer et al, ${ }^{18} 2001$ & 5 & $\begin{array}{l}\text { Ephedrine from ma huang (77.4) } \\
\text { and caffeine from guarana (300) }\end{array}$ & $8 w k$ & 32 & 35 & $0.8(2.4)$ & $4.0(3.4)$ \\
\hline $\begin{array}{l}\text { Buemann et al, }{ }^{19} \\
1994\end{array}$ & 3 & Ephedrine (60) and caffeine (600) & $8 w k$ & 16 & 16 & $7.1(2.4)$ & $8.4(2.4)$ \\
\hline Colker et al,,$^{20} 2001$ & 2 & $\begin{array}{l}\text { Ephedrine from ma huang } \\
\text { (unknown dose) and Coleus } \\
\text { forksohlli (unknown dose) }\end{array}$ & $8 w k$ & 12 & 14 & $0.49(2.35)$ & $2.56(2.35)$ \\
\hline Daly et al, ${ }^{21} 1993$ & 2 & $\begin{array}{l}\text { Ephedrine (150), caffeine (150), and } \\
\text { aspirin (330) }\end{array}$ & $8 w k$ & 15 & 14 & $0.7(2.2)$ & $2.2(2.3)$ \\
\hline $\begin{array}{l}\text { Donikyan } \\
\text { (unpublished data, } \\
\text { 2002) }\end{array}$ & 4 & $\begin{array}{l}\text { Ephedrine from ma huang (72) and } \\
\text { chromium picolinate } \\
(450 \mu \mathrm{g})\end{array}$ & $12 w k$ & 94 & 92 & $1.4(2.7)$ & $3.4(3.1)$ \\
\hline $\begin{array}{l}\text { Greenway et al } \\
\text { (unpublished data) }\end{array}$ & 2 & $\begin{array}{l}\text { Ephedrine from ma huang (72) and } \\
\text { caffeine from unspecified } \\
\text { herb (210) }\end{array}$ & $12 w k$ & 20 & 20 & $0.8(2.6)$ & $3.9(4.0)$ \\
\hline \multirow[t]{2}{*}{ Jensen et al, ${ }^{22} 1980$} & 1 & Ephedrine (100) & $16 w k$ & 17 & 24 & $0.5(4.7)$ & $7.9(4.7)$ \\
\hline & & Ephedrine (100) and caffeine (275) & & & 23 & & $9.4(4.7)$ \\
\hline Kalman et al, ${ }^{23} 2000$ & 3 & $\begin{array}{l}\text { Ephedrine (40), caffeine (400), } \\
\text { synephrine (10), and aspirin (30) }\end{array}$ & $8 w k$ & 14 & 16 & $2.1(2.4)$ & $3.1(2.4)$ \\
\hline Kettle et al, ${ }^{24} 1998$ & 0 & Ephedrine (20) and caffeine (200) & $6 \mathrm{mo}$ & 45 & 45 & $12.8(6.7)$ & $15.6(7.1)$ \\
\hline Lumholtz et al, ${ }^{25} 1980$ & 2 & Ephedrine (120) & $18 w k$ & 63 & 63 & $4.0(5.3)$ & $9.5(5.3)$ \\
\hline $\begin{array}{r}\text { Malchow-Moller } \\
\text { et al, }{ }^{26} 1981 \\
\end{array}$ & 3 & Ephedrine (60) and caffeine (150) & $12 w k$ & 33 & 49 & $4.1(3.5)$ & $8.1(3.5)$ \\
\hline \multirow[t]{2}{*}{ Moheb et al, ${ }^{9} 1998$} & 2 & Ephedrine (150) & $12 w k$ & 32 & 64 & $6.2(3.5)$ & $8.8(3.5)$ \\
\hline & & Ephedrine (150) and caffeine (150) & & & 64 & & $8.9(3.5)$ \\
\hline Molnar et al, ${ }^{27} 2000$ & 4 & $\begin{array}{l}\text { Ephedrine }(30-60) \text { and caffeine } \\
(100 \text { for } 1 \mathrm{wk})\end{array}$ & $20 w k$ & 16 & 16 & $0.5(4.3)$ & $7.9(6.0)$ \\
\hline \multirow[t]{2}{*}{ Pasquali et al, ${ }^{28} 1985$} & 3 & Ephedrine (75) & $3 \mathrm{mo}$ & 21 & 19 & $8.7(3.5)$ & $8.7(2.4)$ \\
\hline & & Ephedrine (150) & & & 22 & & $10.2(3.5)$ \\
\hline \multirow[t]{2}{*}{ Quaade et al, ${ }^{29} 1992$} & 3 & Ephedrine (60) & 24 wk & 45 & 45 & $13.2(6.6)$ & $14.3(5.9)$ \\
\hline & & Ephedrine (60) and caffeine (600) & & & 45 & & $16.6(6.8)$ \\
\hline Roed et al, ${ }^{30} 1980$ & 3 & Ephedrine (120) and caffeine (300) & $12 w k$ & 69 & 69 & $5.2(3.5)$ & $10.0(3.5)$ \\
\hline $\begin{array}{l}\text { Van Mil and Molnar, }{ }^{31} \\
2000\end{array}$ & 1 & Ephedrine (60) and caffeine (600) & $20 w k$ & 16 & 16 & $1.5(8.1)$ & $8.7(5.7)$ \\
\hline
\end{tabular}


(Tenuate). ${ }^{26}$ At 12 weeks of treatment, there was no statistically significant difference in weight loss between groups.

Ephedra vs Placebo. We identified a single trial that assessed ephedra vs placebo (L.A. Donikyan, unpublished data, 2002). This trial was a randomized, double-blind, parallel-group assessment of Metab-O-LITE (Rexall Sundown, Boca Raton, Fla), which contains ephedra and other compounds but caffeine or herbs that contain caffeine. The duration of the trial was 3 months. This trial reported a rate of weight loss of 0.8 $\mathrm{kg}$ per month greater than weight lost with placebo for the group receiving ephedra (95\% CI, 0.4-1.2) (Figure 2). This trial had $17 \%$ attrition.

Ephedra with Herbs Containing Caffeine vs Placebo. We identified 4 trials (3 published ${ }^{17,18,20}$ and 1 unpublished [F. Greenway et al, unpublished data]) that assessed the effect of ephedra with herbs containing caffeine, with results reported at between 2 and 4 months' duration of treatment. All 4 were described as randomized placebocontrolled trials. The pooled randomeffects estimate of the rate of weight loss was $1.0 \mathrm{~kg}$ per month above weight lost with placebo (95\% CI, 0.6-1.3) (Figure 2). The pooled average percent weight loss in the ephedra-treated patients, compared with pretreatment weight, was $5.2 \%$ at 4 months. A sensitivity analysis with only those trials scoring 3 or more on the Jadad scale yielded a result similar to the main analysis. All these studies assessed medium doses of ephedra and therefore no analysis stratified by dose was possible. Neither graphical assessment or statistical tests revealed any evidence of publication bias $(P=.73$ for rank test; $P=.23$ for regression test).

\section{Efficacy: Athletic Performance}

We found 8 published controlled trials $^{33-40}$ of the effects of synthetic ephedrine on athletic performance; most were crossover designs and all but 1 also included caffeine. One study assessed the effect of ephedrine and exercise training on basal metabolic rate, did not report athletic performance out- comes, and is not described below. ${ }^{33}$ The remaining 7 trials were not appropriate for pooled analysis because they involved different types of exercise (power and endurance) and different outcome measures, so they are discussed here individually. We found no trials assessing the effects of herbal ephedra on athletic performance.

Six trials by Bell and colleagues ${ }^{34-39}$ assessed the exercise capacity of small groups of healthy male participants (all trials included 24 participants or fewer) and are summarized in TABLE 2 . These trials reported that neither caffeine nor ephedrine alone had significant effects on parameters of exercise performance such as oxygen consumption, time to exhaustion, or carbon dioxide production, but the combination of ephedrine and caffeine consistently demonstrated a $20 \%$ to $30 \%$ increase in performance. The single trial of strength training did show an improvement in muscle endurance but only on the first of 3 repetitions. In the only trial to test the effects of ephedrine and caffeine on thermal regulation, no increase in temperature was reported. Nausea and vomiting were reported in a third of the participants given ephedrine at a dose of $1 \mathrm{mg} / \mathrm{kg}$ with 5 $\mathrm{mg} / \mathrm{kg}$ of caffeine, but not in any of those given a lower dose of $0.8 \mathrm{mg} / \mathrm{kg}$ of ephedrine and $4 \mathrm{mg} / \mathrm{kg}$ of caffeine.

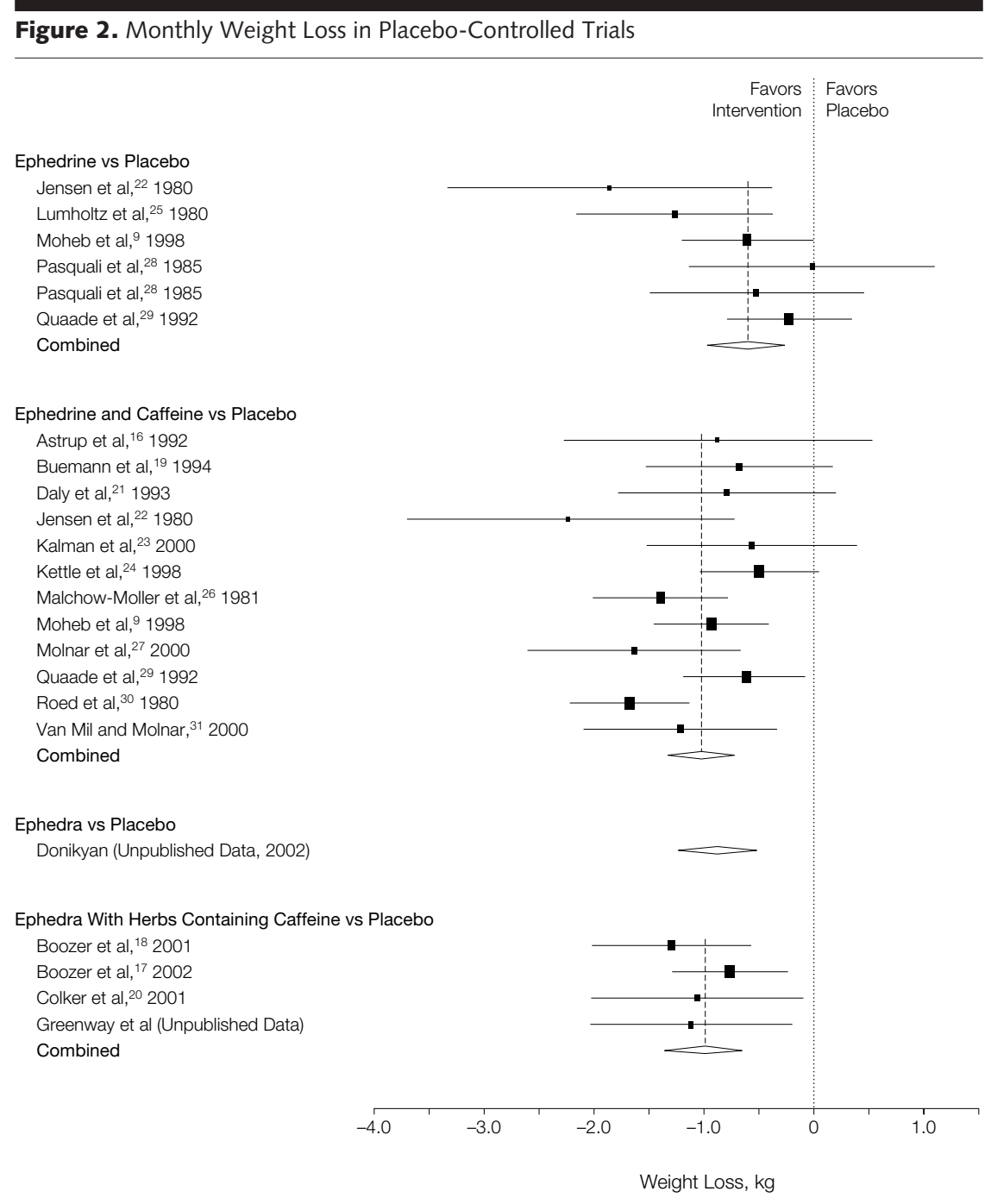

Sizes of boxes correspond to sample sizes. Error bars indicate $95 \%$ confidence intervals. 
One other trial was identified. It reported no statistically significant improvement in a battery of tests of physical function including oxygen uptake, measures of endurance and power, reaction time, hand-eye coordination, speed, and self-perceived exertion. ${ }^{40}$

\section{Safety Assessment: Randomized Trials}

Two of 52 trials were excluded from the OR analysis because they did not have a placebo group. ${ }^{32,41}$ There were numerous symptoms reported as adverse events in the remaining 50 trials of ephedra and ephedrine. We grouped clinically similar symptoms into 7 categories: (1) psychiatric symptoms, ie, those described in the original clinical trials as "euphoria," "neurotic behavior," "agitation," "neuropsychiatric," "depressed mood," "giddiness," "irritability," and "anxiety;" (2) autonomic hyperactivity symptoms, ie, those described in the original clinical trials as "tremor," "twitching," "jitteri- ness," "insomnia," "difficulty sleeping," "increased sweating," "increased perspiration," and "sweating;" (3) upper gastrointestinal symptoms, ie, those described in the original clinical trials as "nausea," "vomiting," "abdominal pain," "upset stomach," "heartburn," and "gastroesophageal reflux;" (4) palpitations, ie, those symptoms described in the original clinical trials as "palpitations," "irregular heartbeat," "loud heartbeat," "heart pounding," and "increased or stronger heartbeat;" (5) tachycardia, ie, those symptoms described in the original clinical trials as "tachycardia" and "slightly elevated heart rate;" (6) hypertension, ie, those symptoms described in the original clinical trials as "hypertension," "increased systolic blood pressure," and "increased diastolic blood pressure;" and (7) headache.

TABLE 3 presents the pooled estimate of the OR for each of those adverse events for which there were sufficient data to justify attempting meta-analysis. The OR will slightly overestimate the risk ratio for these events, because they occur in $10 \%$ to $20 \%$ of participants. Participants in active treatment had between 2.2 and 3.6 increased odds for the adverse events of psychiatric symptoms, autonomic hyperactivity, upper gastrointestinal symptoms, and heart palpitations. There was a trend toward an increase of similar magnitude in the report of hypertension, but this increase was not statistically significant. In our dose analysis, there was a trend toward higher risk of adverse events with higher doses of ephedrine, but data were sparse and these differences were not statistically significant (for example, adjusted ORs of autonomic hyperactivity were 2.7 and 10.4 for medium- and high-dose ephedrine, respectively, but the $95 \%$ CIs overlapped). It is not possible to estimate the degree to which caffeine contributes to these results, because there were too few trials of ephedrine alone or ephedra alone to support

\begin{tabular}{|c|c|c|c|}
\hline Source & $\begin{array}{l}\text { Compounds Received by } \\
\text { Comparison Groups }\end{array}$ & Exercise Type & Results \\
\hline Bell et al, ${ }^{34} 1998$ & $\begin{array}{l}\text { Placebo } \\
\text { Ephedrine }(1 \mathrm{mg} / \mathrm{kg}) \\
\text { Caffeine }(5 \mathrm{mg} / \mathrm{kg}) \\
\text { Ephedrine }(1 \mathrm{mg} / \mathrm{kg}) \text { and } \\
\quad \text { caffeine }(5 \mathrm{mg} / \mathrm{kg})\end{array}$ & $\begin{array}{l}\text { Cycle ergometer trials to } \\
\text { exhaustion }\end{array}$ & $\begin{array}{l}\text { Ephedrine and caffeine significantly } \\
\text { increased time to exhaustion } \\
\text { compared with placebo. Heart rate } \\
\text { during exercise was significantly } \\
\text { increased for ephedrine and caffeine, } \\
\text { caffeine groups. }\end{array}$ \\
\hline Bell and Jacobs, ${ }^{35} 1999$ & $\begin{array}{l}\text { Placebo } \\
\text { Ephedrine }(75 \mathrm{mg}) \text { and } \\
\quad \text { caffeine }(375 \mathrm{mg})\end{array}$ & $\begin{array}{l}\text { Canadian Forces Warrior Test } \\
\text { (3.2-km run wearing } 11 \mathrm{~kg} \text { of } \\
\text { equipment) }\end{array}$ & $\begin{array}{l}\text { Run times for ephedrine and caffeine trial } \\
\text { were significantly faster than those } \\
\text { for control and placebo trials. }\end{array}$ \\
\hline Bell et al, ${ }^{36} 1999$ & $\begin{array}{l}\text { Placebo } \\
\text { Ephedrine }(1 \mathrm{mg} / \mathrm{kg}) \text { and } \\
\quad \text { caffeine }(5 \mathrm{mg} / \mathrm{kg})\end{array}$ & $\begin{array}{l}\text { Treadmill walking at } 50 \% \mathrm{VO}_{2} \\
\text { peak, } 40^{\circ} \mathrm{C} \text { climate, } 30 \% \\
\text { relative humidity }\end{array}$ & $\begin{array}{l}\text { Ephedrine and caffeine did not } \\
\text { significantly change tolerance times } \\
\text { when compared with placebo. } \\
\text { Ephedrine and caffeine did not affect } \\
\text { skin or rectal temperature, sweat } \\
\text { rate, or sensation of thermal comfort. }\end{array}$ \\
\hline Bell et al, ${ }^{37} 2000$ & $\begin{array}{l}\text { Placebo } \\
\text { Caffeine }(5 \mathrm{mg} / \mathrm{kg}) \text { and } \\
\quad \text { ephedrine }(0.8 \mathrm{mg} / \mathrm{kg}) \\
\text { Caffeine }(4 \mathrm{mg} / \mathrm{kg}) \text { and } \\
\quad \text { ephedrine }(1 \mathrm{mg} / \mathrm{kg}) \\
\text { Caffeine }(4 \mathrm{mg} / \mathrm{kg}) \text { and } \\
\quad \text { ephedrine }(0.8 \mathrm{mg} / \mathrm{kg})\end{array}$ & $\begin{array}{l}\text { Cycle ergometer trials to } \\
\text { exhaustion at } 85 \% \mathrm{VO}_{2} \text { peak }\end{array}$ & $\begin{array}{l}\text { A lower dose of ephedrine and caffeine } \\
\text { resulted in ergogenic effect similar in } \\
\text { magnitude as reported previously } \\
\text { with a higher dose, while fewer } \\
\text { adverse effects were reported. }\end{array}$ \\
\hline Pasternak et al, ${ }^{38} 1999$ & $\begin{array}{l}\text { Placebo } \\
\text { Ephedrine }(0.8 \mathrm{mg} / \mathrm{kg}) \\
\text { Caffeine }(4 \mathrm{mg} / \mathrm{kg}) \\
\text { Ephedrine }(0.8 \mathrm{mg} / \mathrm{kg}) \text { and } \\
\quad \text { caffeine }(4 \mathrm{mg} / \mathrm{kg})\end{array}$ & $\begin{array}{l}\text { Three supersets of leg press and } \\
\text { bench press, to exhaustion }\end{array}$ & $\begin{array}{l}\text { Ephedrine and ephedrine and caffeine } \\
\text { increased muscular endurance, but } \\
\text { only in the first set. Systolic blood } \\
\text { pressure was increased with } \\
\text { ephedrine and with ephedrine and } \\
\text { caffeine. }\end{array}$ \\
\hline Bell et al, ${ }^{39} 2001$ & $\begin{array}{l}\text { Placebo } \\
\text { Ephedrine }(1 \mathrm{mg} / \mathrm{kg}) \\
\text { Caffeine }(5 \mathrm{mg} / \mathrm{kg}) \\
\text { Ephedrine } 1(\mathrm{mg} / \mathrm{kg}) \text { and } \\
\quad \text { caffeine }(5 \mathrm{mg} / \mathrm{kg})\end{array}$ & $\begin{array}{l}\text { Two different cycle ergometer } \\
\text { tests, with } 1 \text { to exhaustion at } \\
125 \% \mathrm{VO}_{2} \text { peak }\end{array}$ & $\begin{array}{l}\text { Ephedrine improved performance during } \\
\text { Wingate test of anaerobic power. } \\
\text { Caffeine increased time to } \\
\text { exhaustion in second test. }\end{array}$ \\
\hline
\end{tabular}


stratified analyses. The 1 trial of herbal ephedra without herbs containing caffeine reported a statistically significant 2-fold increase in gastrointestinal symptoms.

If we consider all 1706 patients in the treatment groups of all 52 trials, these trials have at least $80 \%$ power to distinguish a serious adverse event rate of 1.0 per thousand or higher. Thus, though we observed no serious adverse events in any of these trials, the relatively small aggregated sample size across the treatment groups in all trials limits the strength of our conclusions.

\section{Safety Assessment: Case Reports}

We reviewed 71 case reports in the published literature, 1820 case reports in the FDA MedWatch files, and 15951 cases reported to 1 manufacturer of ephedra-containing dietary supplements. The majority of case reports are insufficiently documented to make an informed judgment about a relationship between the use of ephedrine- or ephedra-containing dietary supplements and the adverse event in question. From the unpublished reports, 284 concerned serious adverse events and had sufficient evidence to warrant de- tailed review. We identified 2 deaths, 3 myocardial infarctions, 9 cerebrovascular accidents, 3 seizures, and 5 psychiatric cases as sentinel events with prior ephedra consumption; and 3 deaths, 2 myocardial infarctions, 2 cerebrovascular accidents, 1 seizure, and 3 psychiatric cases as sentinel events with prior ephedrine consumption. We identified an additional 43 and 7 cases as possible sentinel events with prior ephedra and ephedrine consumption, respectively. About half of sentinel events occurred in persons aged 30 years or younger (TABLE 4). Full details are

Table 3. Summary of Meta-analysis of Adverse Events Reporting in Controlled Trials

\begin{tabular}{|c|c|c|c|c|c|c|}
\hline \multirow[b]{3}{*}{ Adverse Event* } & \multirow[b]{3}{*}{ No. of Studies } & \multirow{2}{*}{\multicolumn{2}{|c|}{ Sample Size, No. }} & \multicolumn{3}{|c|}{ Adverse Events } \\
\hline & & & & & & \multirow[b]{2}{*}{ Pooled OR $(95 \% \mathrm{Cl})$} \\
\hline & & Placebo & Intervention & Placebo & Intervention & \\
\hline Psychiatric symptoms & 8 & 273 & 351 & 16 & 59 & $3.64(1.91-7.31)$ \\
\hline Autonomic hyperactivity & 13 & 365 & 587 & 39 & 138 & $3.37(2.19-5.31)$ \\
\hline Heart palpitations & 11 & 386 & 563 & 18 & 51 & $2.29(1.27-4.32)$ \\
\hline Hypertension & 5 & 257 & 305 & 3 & 7 & $2.19(0.49-13.34)$ \\
\hline Upper Gl symptoms & 10 & 432 & 568 & 46 & 88 & $2.15(1.39-3.38)$ \\
\hline Headache & 5 & 123 & 185 & 8 & 16 & $1.64(0.62-4.68)$ \\
\hline Tachycardia & 1 & 45 & 90 & 0 & 6 & NR \\
\hline
\end{tabular}

Abbreviations: $\mathrm{Cl}$, confidence interval; Gl, gastrointestinal; NR, not reported; OR, odds ratio.

*A study may contribute adverse events to more than 1 category.

Table 4. Summary of Adverse Events With Consumption of Ephedra or Ephedrine

\begin{tabular}{|c|c|c|c|c|c|c|c|c|c|c|}
\hline \multirow[b]{2}{*}{ Demographics } & \multicolumn{2}{|c|}{ Death } & \multicolumn{2}{|c|}{$\begin{array}{c}\text { Myocardial } \\
\text { Infarction/Other } \\
\text { Cardiac }\end{array}$} & \multicolumn{2}{|c|}{$\begin{array}{c}\text { Cerebrovascular } \\
\text { Accident/ } \\
\text { Other Neurologic }\end{array}$} & \multicolumn{2}{|c|}{ Seizure } & \multicolumn{2}{|c|}{$\begin{array}{l}\text { Psychiatric } \\
\text { Symptoms }\end{array}$} \\
\hline & Ephedra & Ephedrine & Ephedra & Ephedrine & Ephedra & Ephedrine & Ephedra & Ephedrine & Ephedra & Ephedrine \\
\hline $\begin{array}{l}\text { Total events, No. } \\
\text { Sentinel }\end{array}$ & 2 & 3 & 3 & 2 & 9 & 2 & 3 & 1 & 5 & 3 \\
\hline Possible sentinel & 9 & 3 & 9 & 1 & 11 & 2 & 7 & 0 & 7 & 1 \\
\hline $\begin{array}{c}\text { Events by sex, No. } \\
\text { Women } \\
\text { Sentinel }\end{array}$ & 1 & 1 & 0 & 2 & 5 & 2 & 3 & 1 & 2 & 1 \\
\hline Possible sentinel & 3 & 1 & 4 & 1 & 8 & 0 & 5 & 0 & 4 & 0 \\
\hline $\begin{array}{l}\text { Men } \\
\quad \text { Sentinel }\end{array}$ & 1 & 2 & 3 & 0 & 4 & 0 & 0 & 0 & 3 & 2 \\
\hline Possible sentinel & 6 & 2 & 5 & 0 & 3 & 2 & 2 & 0 & 3 & 1 \\
\hline $\begin{array}{c}\text { Events by age, No. } \\
13-30 y \\
\text { Sentinel }\end{array}$ & 2 & 2 & 2 & 1 & 3 & 2 & 2 & 0 & 3 & 2 \\
\hline Possible sentinel & 5 & 0 & 1 & 1 & 2 & 1 & 3 & 0 & 5 & 0 \\
\hline $\begin{array}{l}\text { 31-50 y } \\
\text { Sentinel }\end{array}$ & 0 & 1 & 1 & 1 & 5 & 0 & 1 & 1 & 2 & 0 \\
\hline Possible sentinel & 4 & 2 & 7 & 0 & 5 & 1 & 3 & 0 & 1 & 1 \\
\hline $\begin{array}{l}\text { 51-70 y } \\
\text { Sentinel }\end{array}$ & 0 & 0 & 0 & 0 & 1 & 0 & 0 & 0 & 0 & 1 \\
\hline Possible sentinel & 0 & 1 & 1 & 0 & 4 & 0 & 1 & 0 & 1 & 0 \\
\hline
\end{tabular}


available at http://www.ahrq.gov/clinic levrptfiles.html\#ephedra.

\section{COMMENT}

We found sufficient evidence to conclude that the short-term use of ephedrine at high doses, or of ephedrine and caffeine, ephedra, and ephedra with herbs containing caffeine, promotes weight loss in selected patient populations. These results satisfy, with 1 exception, published criteria ${ }^{42}$ for the evaluation of weight loss products, as they are randomized, blinded, placebocontrolled, and resulted in a weight loss of at least $5 \%$ of pretreatment weight. The criterion not met is duration of treatment, as all trials but 3 reported less than 6 months duration of treatment. Trials assessing 1 year of treatment are considered desirable, as are trials assessing what happens to weight after the weight loss product is discontinued.

We can also conclude that caffeine adds additional efficacy to ephedrine in promoting weight loss, and the effects of ephedrine and caffeine and ephedra with or without herbs containing caffeine are approximately equivalent, each resulting in about $0.9 \mathrm{~kg}$ per month of weight loss above that lost with placebo, extending out to 4 months. To help put these data in context, placebocontrolled studies of some FDAapproved weight loss pharmacotherapies have reported losses 2.7 to $4.5 \mathrm{~kg}$ greater than losses with placebo over 6 to 12 months for patients taking sibutramine $e^{43-46}$ or orlistat ${ }^{47-51}$; or $7.2 \mathrm{~kg}$ greater than with placebo at 9 months for patients taking phentermine. ${ }^{52}$ There are no data regarding weight loss beyond 6 months' use of ephedrine or ephedra.

Regarding athletic performance, we were unable to identify any controlled trials of ephedra. The few identified trials of ephedrine did not study it as used by the general population, that is, repeated use. Therefore, the effect of ephedra or ephedrine as it is used to promote enhanced athletic performance is unknown.

We found sufficient evidence to conclude that ephedrine and ephedra are associated with 2 to 3 times the risk of psychiatric symptoms, autonomic symptoms, upper gastrointestinal symptoms, and heart palpitations. It is not possible to separate out the effect caffeine may contribute to these events. As most ephedra-containing dietary supplements also contain herbs with caffeine, this issue may be moot. We also found a number of case reports of serious adverse events that occurred in young adults without apparent causes. Similar observations have been made by oth$\mathrm{ers}^{2}$ and raise the possibility that there may be a causal relationship between ephedrine or ephedra use and rare serious adverse events. A recent casecontrol study reported an adjusted OR of 3.59 (95\% CI, 0.70-18.35) for hemorrhagic stroke in persons taking more than $32 \mathrm{mg} / \mathrm{d}$ of ephedra. We note that we found no studies of ephedra where participants consumed less than $32 \mathrm{mg} / \mathrm{d}$ of ephedra. ${ }^{53}$ In addition, another recent report linked ephedra use to an increased risk of adverse events reported to poison control centers, relative to other herbal products. ${ }^{54}$

Our study has several limitations. Many of the trials had methods problems. However, not all trials did, and our sensitivity analyses of the higherquality trials supported our main analysis with respect to ephedrine and caffeine and with respect to ephedra. Only for ephedrine alone did we find evidence that higher-quality trials reported smaller effects, as has been reported in meta-analyses of other clinical questions. ${ }^{11}$ Second, while we did not find any evidence of publication bias, this does not mean that it does not exist. There is no way of ever knowing if all trials conducted have been identified. We made reasonable efforts to identify and did identify some unpublished data. Third, we did not observe significant heterogeneity among the weight loss trials but acknowledge that the $\chi^{2}$ test of heterogeneity is underpowered. We used a random-effects approach and sensitivity analysis to try to incorporate and understand possible heterogeneity. The heterogeneity among the athletic performance trials prevented us from conducting a for- mal meta-analysis at all. Fourth, the generalizability of the results to the use of ephedra or ephedrine in a general population may not be valid. The weight loss trials frequently involved medical screening to detect preexisting conditions, such as heart disease, that may predispose subjects to an increased risk of adverse events. Such patients were then excluded from the trials. Whether patients taking ephedra or ephedrine without such medical screening have a similar risk of adverse events is unknown. Finally, the weight loss trials as a group had limited duration of treatment times and thus we cannot draw conclusions about the association between ephedra and weight loss over longer and more clinically relevant intervals than about 4 months, nor about what happens to weight after the ephedra or ephedrine is stopped.

With these limitations in mind we found sufficient evidence to conclude that ephedrine- and ephedra-containing dietary supplements have modest short-term benefits with respect to weight loss and have harms in terms of a 2- to 3-fold increase in psychiatric symptoms, autonomic symptoms, upper gastrointestinal symptoms, and heart palpitations. More serious adverse effects from ephedra use cannot be excluded at a rate less than 1.0 per thousand, and case reports raise the possibility that a causal relationship with serious adverse events may exist. We did not find sufficient evidence to support the use of ephedra for enhancing athletic performance.

Author Affiliations: Southern California Evidencebased Practice Center-RAND, Santa Monica, Calif (Drs Shekelle, Morton, Mojica, and Mss Maglione, Suttorp, Rhodes, and Jungvig); Cedars-Sinai Medical Center, Los Angeles, Calif (Dr Hardy); Greater Los Angeles Veterans Affairs Healthcare System (Dr Shekelle); and Department of Family Medicine, University of Southern California, Los Angeles (Dr Gagné). Author Contributions: Study concept and design: Shekelle, Hardy, Morton, Maglione, Suttorp. Acquisition of data: Shekelle, Hardy, Morton, Maglione, Mojica, Suttorp, Rhodes, Gagné. Analysis and interpretation of data: Shekelle, Hardy, Morton, Maglione, Suttorp, Jungvig.

Drafting of the manuscript: Shekelle, Morton, Suttorp, Rhodes, Jungvig.

Critical revision of the manuscript for important intellectual content: Shekelle, Hardy, Morton, Maglione, Mojica, Suttorp, Jungvig, Gagné. 
Statistical expertise: Shekelle, Morton, Suttorp. Obtained funding: Shekelle, Hardy, Morton, Maglione. Administrative, technical, or material support: Shekelle, Maglione, Mojica, Suttorp, Rhodes, Jungvig. Study supervision: Shekelle, Morton, Maglione, Mojica. Funding/Support: This research was performed by the Southern California Evidence-based Practice Center-
RAND, Santa Monica, Calif, under Agency for Healthcare Research and Quality contract 290-97-0001. Disclaimer: The authors of this article are responsible for its contents. No statement in this article should be construed as an official position of the Agency for Healthcare Research and Quality or of the US Department of Health and Human Services.
Acknowledgment: We thank Birgit Danila, MA, for translation of Danish trials, and Elizabeth Roth for programming advice. We also thank the members of our Technical Expert Panel who advised us on the project and reviewed our findings. Dr Shekelle was a Senior Research Associate of the Veterans Affairs Health Services Research and Development Service.

\section{REFERENCES}

1. Abrahamson A. Wheeler used supplement. LoS Angeles Times. August 11, 2001; Sports section: D1, D9.

2. Haller CA, Benowitz NL. Adverse cardiovascular and central nervous system events associated with dietary supplements containing ephedra alkaloids. N Eng/ Med. 2000:343:1833-1838.

3. Carey B. Risks of ephedra usage in spotlight. Los Angeles Times. August 27, 2001; Health section: D11, D13.

4. Public Citizen. Public Citizen Calls On FDA To Ban Dietary Supplements Containing Ephedra. September 5, 2001. Available at: http://www.citizen.org /pressroom/release.cfm?ID $=654$. Accessibility verified February 17, 2003.

5. Marsa L. A tug of war in a larger battle: ephedra is now under intense scrutiny. Los Angeles Times. September 2, 2002: Health section:D10, D12.

6. Department of Health and Human Services. HHS announces plans to study ephedra. HHS News. June 14, 2002. Available at: http://www.hhs.gov/news /press/2002press/20020614.html. Accessibility verified February 17, 2003.

7. DerSimonian R, Laird N. Meta-analysis in clinical trials. Control Clin Trials. 1986:7:177-188.

8. Berkey CS, Hoaglin DC, Mosteller F, Colditz GA. A random-effects regression model for metaanalysis. Stat Med. 1995:14:395-411.

9. Moheb MA, Geissler CA, Lancer K. Effect of ephedrine, caffeine, and aspirin, in combinations of weight loss in obese women [abstract]. Int J Obes Relat Metab Disord. 1998:22(suppl 3):S264.

10. Jadad AR, Moore RA, Carroll D, et al. Assessing the quality of reports of randomized clinical trials: is blinding necessary? Control Clin Trials. 1996;17: $1-12$

11. Moher D, Pham B, Jones A, et al. Does quality of reports of randomised trials affect estimates of intervention efficacy reported in meta-analyses? Lancet. 1998;352:609-613.

12. Begg CB, Mazumdar M. Operating characteristics of a rank correlation test for publication bias. Biometrics. 1994:50:1088-1101.

13. Egger M, Davey Smith G, Schneider M, Minder $C$. Bias in meta-analysis detected by a simple, graphical test. BMJ. 1997:315:629-634.

14. Stata [computer program]. Release 7.0. College Station, Tex: Stata Corp; 2001.

15. StatXact 4 [computer program]. Version 4.0. Cambridge, Mass: Cytel Software Corp; 2000.

16. Astrup A, Buemann B, Christensen NJ, et al. The effect of ephedrine/caffeine mixture on energy expenditure and body composition in obese women. Metabolism. 1992;41:686-688.

17. Boozer CN, Daly PA, Homel P, et al. Herbal ephe$\mathrm{dra} /$ caffeine for weight loss. Int J Obes Relat Metab Disord. 2002:26:593-604.

18. Boozer CN, Nasser JA, Heymsfield SB, Wang V, Chen G, Solomon JL. An herbal supplement containing Ma Huang-Guarana for weight loss. Int J Obes Relat Metab Disord. 2001;25:316-324.

19. Buemann B, Marckmann P, Christensen NJ, Astrup $A$. The effect of ephedrine plus caffeine on plasma lipids and lipoproteins during a 4.2 MJ/day diet. Int J Obes Relat Metab Disord. 1994;18:329-332.

20. Colker CM, Swain MA, Lynch L. A pilot study evaluating the effects of an ephedrine and forskolinbased product on body weight and body composition in overweight, healthy women [abstract]. J Am Coll Nutr. 2001;20:98.

21. Daly PA, Krieger DR, Dulloo AG, Young JB, Landsberg L. Ephedrine, caffeine and aspirin. Int J Obes Relat Metab Disord. 1993:17(suppl 1):S73-S78.

22. Jensen KB, Dano P, Draeby N, Hansen SH, Kanstrup J. Elsinore tablets and ephedrine as slimming agents [in Danish]. Ugeskr Laeger. 1980;142:1499-1501.

23. Kalman DS, Colker CM, Shi Q, Swain MA. Effects of a weight-loss aid in healthy overweight adults. Curr Ther Res Clin Exp. 2000;61:199-205.

24. Kettle R, Toubro S, Astrup A. Ephedrine/ caffeine enhances abdominal fat loss in females. Int $\rfloor$ Obes Relat Metab Disord. 1998;22(suppl 3):S264. 25. Lumholtz IB, Thorsteinsson B, Wamberg T, et al. Ephedrine in the treatment of obesity [in Danish]. Ugeskr Laeger. 1980;142:1487-1490.

26. Malchow-Moller A, Larsen S, Hey H, Stokholm KH, Juhl E, Quaade F. Ephedrine as an anorectic: the story of the "Elsinore pill." Int J Obes. 1981:5:183-187. 27. Molnar D, Torok K, Erhardt E, Jeges S. Safety and efficacy of treatment with an ephedrine/caffeine mixture. Int J Obes Relat Metab Disord. 2000;24:15731578

28. Pasquali R, Baraldi G, Cesari MP, et al. A controlled trial using ephedrine in the treatment of obesity. Int J Obes. 1985:9:93-98.

29. Quaade F, Astrup A, Breum L, Toubro S, Hein P. The effect of an ephedrine/caffeine combination as a supplement to a weight-reducing diet [in Danish]. Ugeskr Laeger. 1992;154:1258-1263.

30. Roed P, Hansen PW, Bidstrup B, Kaern M, Helles A, Petersen KP. Elsinore banting tablets [in Danish]. Jgeskr Laeger. 1980;142:1491-1495.

31. Van Mil E, Molnar D. Drug treatment in obese adolescents [abstract]. Int J Obes. 2000;24(suppl 1): S184.

32. Breum L, Pedersen JK, Ahlstrom F, Frimodt-Moller J. Comparison of an ephedrine/caffeine combination and dexfenfluramine in the treatment of obesity. Int J Obes Relat Metab Disord. 1994;18:99-103.

33. Oksbjerg N, Meyer T, Hvid-Jacobsen K. Aerobic training increases the effect of ephedrine on energy expenditure [in Danish]. Ugeskr Laeger. 1986;148: 2021-2024.

34. Bell DG, Jacobs I, Zamecnik J. Effects of caffeine, ephedrine and their combination on time to exhaustion during high-intensity exercise. Eur J Appl Physiol Occup Physiol. 1998;77:427-433.

35. Bell DG, Jacobs I. Combined caffeine and ephedrine ingestion improves run times of Canadian Forces Warrior Test. Aviat Space Environ Med 1999:70:325-329. 36. Bell DG, Jacobs I, McLellan TM, Miyazaki M, Sabiston CM. Thermal regulation in the heat during exercise after caffeine and ephedrine ingestion. Aviat Space Environ Med. 1999;70:583-588.

37. Bell DG, Jacobs I, McLellan TM, Zamecnik J. Reducing the dose of combined caffeine and ephedrine preserves the ergogenic effect. Aviat Space Environ Med. 2000;71:415-419.

38. Pasternak $\mathrm{H}$, Jacobs I, Bell D. Effects of ingesting caffeine and ephedrine on muscular endurance. Can J Appl Physiol. 1999;24:471.

39. Bell DG, Jacobs I, Ellerington K. Effect of caffeine and ephedrine ingestion on anaerobic exercise performance. Med Sci Sports Exerc. 2001;33:1399-1403

40. Sidney KH, Lefcoe NM. The effects of ephedrine on the physiological and psychological responses to submaximal and maximal exercise in man. Med Sci Sports. 1977;9:95-99.

41. Toubro S, Astrup A. Randomised comparison of diets for maintaining obese subjects' weight after major weight loss. BMJ. 1997;314:29-34.

42. Bray GA. Evaluation of drugs for treating obesity. Obes Res. 1995:3(suppl 4):425S-434S

43. Fujioka K, Seaton TB, Rowe E, et al. Weight loss with sibutramine improves glycaemic control and other metabolic parameters in obese patients with type 2 diabetes mellitus. Diabetes Obes Metab. 2000;2:175-187.

44. Gokcel A, Karakose H, Ertorer EM, Tanaci N, Tutuncu NB, Guvener N. Effects of sibutramine in obese female subjects with type 2 diabetes and poor blood glucose control Diabetes Care. 2001:24:1957-1960.

45. Smith IG, Goulder MA. Randomized placebo controlled trial of long-term treatment with sibutramine in mild to moderate obesity. J Fam Pract. 2001 50:505-512

46. Wirth $A$, Krause J. Long-term weight loss with sibutramine. JAMA. 2001;286:1331-1339.

47. Van Gaal LF, Broom JI, Enzi G, Toplak $\mathrm{H}$, for the Orlistat Dose-Ranging Study Group. Efficacy and tolerability of orlistat in the treatment of obesity. Eur Clin Pharmacol. 1998:54:125-132.

48. Hill JO, Hauptman J, Anderson JW, et al. Orlistat, a lipase inhibitor, for weight maintenance after conventional dieting: a 1-y study. Am J Clin Nutr. 1999 69:1108-1116.

49. Karhunen L, Franssila-Kallunki $A$, Rissanen $P$, et al. Effect of orlistat treatment on body composition and resting energy expenditure during a two-year weight-reduction programme in obese Finns. Int J Obes Relat Metab Disord. 2000;24:1567-1572.

50. Micic D, Ivkovic-Lazar T, Dragojevic R, et al. Orlistat, a gastrointestinal lipase inhibitor, in therapy of obesity with concomitant hyperlipidemia [in SerboCroatian]. Med Pregl. 1999;52:323-333.

51. Muls E, Kolanowski J, Scheen A, Van Gaal L. The effects of orlistat on weight and on serum lipids in obese patients with hypercholesterolemia. Int J Obes Relat Metab Disord. 2001;25:1713-1721.

52. Munro JF, MacCuish AC, Wilson EM, Duncan LJ. Comparison of continuous and intermittent anorectic therapy in obesity. BMJ. 1968;1:352.

53. Morgenstern LB, Viscoli CM, Kernan WN, et al. Use of ephedra-containing products and risk for hemorrhagic stroke. Neurology. 2003;60:132-135. 54. Bent S, Tiedt TN, Odden MC, Shlipak MG. The relative safety of ephedra compared with other herbal products. Available at: http://www.acponline.org /journals/annals/ephedra.htm?hp. Accessibility verified February 17, 2003 